\title{
Study on the calculation and distribution of value- added benefits between regional industries water rights transaction
}

Wenge Zhang ( $\square$ zhangwenge@yeah.net )

Yellow River Institute of Hydraulic Research

Qiongying Du

Zhengzhou University

Xinjian Guan

Zhengzhou University

Baoyong Wang

Zhengzhou University

Research Article

Keywords:

Posted Date: February 22nd, 2022

DOI: https://doi.org/10.21203/rs.3.rs-1364854/v1

License: (c) (i) This work is licensed under a Creative Commons Attribution 4.0 International License. Read Full License 
1 Study on the calculation and distribution of value-added benefits between regional industries water rights transaction

zhangwenge@yeah.net

(W.Zhang); dqy13783451709@163.com

(Q.Du); gxj1016@zzu.edu.cn (X.Guan); wangbaoyong2020@163.com

(B.Wang); Present/permanent address:

No. 45 Shunhe Road, Jinshui District, Zhengzhou City, Henan Province, China, 450003, PR China

Abstract: As an important means of optimizing the allocation of water resources, the continuous development of water rights transaction has a stronger demand for fair distribution of benefits among participants. In this paper, the marginal benefit of agricultural and industrial water is calculated based on the Cobb-Douglas production function, and the benefit increment of water rights trade from agriculture to industry

* Corresponding author.

E-mail address: zhangwenge@yeah.net (W.Zhang). 
is calculated based on the tradable water volume. Meanwhile, the improved Shapley value method is used to distribute benefits between regional industries, which considers the impact of investment factors and risk factors on the distribution of benefits compared with the traditional Shapley value method. Taking Ordos City in Inner Mongolia as an example, the calculation results show that the marginal benefit of industrial water is $157.94 \mathrm{RMB} / \mathrm{m}^{3}$, which is far greater than the marginal benefit of agricultural water of $4.27 \mathrm{RMB} / \mathrm{m}^{3}$, and the water right trade improves the use value of water resources. The improved Shapley value method can allocate 39.058 hundred million RMB and 97.032 hundred million RMB to agriculture and industry respectively, which improves the allocation weight of industry compared with the original Shapley value method. The study on the increment and distribution of the benefits of water rights transaction between regional industries proposed in this paper, can provide a reference for the income distribution of all parties in the practice of water rights transactions and promote the sustainable development of water rights transactions.

Key words: Improved Shapley value method, Benefit increment distribution, Between regional industries, Water rights transaction

\section{Introduction}

Water rights transaction is an effective means for the market to optimize the allocation of water resources. The essence of inter industry water rights transaction is the transfer and utilization of water resources among different industries, which can not only solve the problem of water shortage in the industry, but also promote the 
efficient utilization of water resources and improve the allocation efficiency of water resources. The research on the benefit increment calculation and distribution of value-added benefits between regional industries water rights transaction can not only directly reflect the economic benefits brought by water rights transaction, but also provide theoretical support for the fair sharing of the interests of various subjects and the coordinated development between regional industries.

Since China implemented the reform of water right system in the 21 st century, many scholars have made efforts to improve the theory and system of water rights, and a series of achievements have been made in the theory and method of water right transaction. Water rights transaction is mainly to transfer water from low-income use to high-income use, which will increase water productivity and the interests of the whole region (Easter et al. 1998; Ringler. 2001). The exploration of water rights transaction mode and mechanism, including water rights transaction among agricultural water users (Tan. 2019; Hu et al. 2010), water rights transaction between regional industries (Liu 2018), cross regional water rights transaction (Zhang 2019) and buy back water rights from government departments (Wang \& Yang. 2018). These are the landscaping spot transaction, and some scholars introduced the concept of water level later (Gu 2019), which is a supplement to the research of China's water rights transaction market. The object of the transaction has developed from one-dimensional water volume transaction to two variable water rights transaction considering water quality and quantity (Kuang. 2015; Guo et al. 2021; Zhang et al. 2020). Zhang JB (2018) and others carried out research on the construction of 
two-dimensional water rights market transaction model in the Yellow River Area of Inner Mongolia. The income mechanism of water rights transaction is an important factor to promote the long-term sustainable development of transaction. Meng G's (2009) research shows that water rights transaction can not only improve the overall use efficiency of water resources, but also improve the net income of water users. The research on the water market in California shows that the main factor affecting farmers' water right transfer is the transaction income (Archibald \& Renwick. 1998). Lin et al. (2000) pointed out that the rationality of water right income will affect the long-term nature of agricultural water rights transfer.

For the quantitative calculation of income, most studies focus on the formulation of transaction price, which can be based on the shadow price (Wu \& Li. 2019) or cost between the buyer and the seller. In addition, there are theories such as negotiation (Tian \& Wei. 2019) and game pricing (Liu et al. 2017; Chen et al. 2006). Further research is to compensate the interests of relevant subjects. For example, Chen JH (2008) studied the compensation mechanism of water resources from agriculture to Africa and non-agricultural industries to the agricultural sector. At present, there is a lack of research on the value-added accounting and distribution of direct benefits brought by water rights transaction. However, the continuous incentive of agricultural water saving and water rights transaction needs to distribute the benefits to all interested parties in a fair and effective way. Cooperative game theory (Curiel 1997; Dimitrov 2005), especially Shapley value method, provides an effective method to achieve this goal. Cooperative game theory is often used in the 
income distribution of PPP projects and enterprise cooperation. At present, this method has been applied to the field of water resources (Parrachino et al. 2006). For example, Ma YX (2016) studied the benefit distribution of cross regional transfer of water resources with Shapley value method.

Taking the inter industry water rights transaction as the research object, this paper first calculates the unilateral water marginal benefits of industry and agriculture in the study area based on the production function, and then calculates the added value of benefits from agriculture to industrial water rights transaction according to the tradable water volume. After that, considering the influence of input factors and risk factors, this paper improves the traditional Shapley value method, establishes a fair and reasonable benefit value-added distribution model of inter industry water rights transaction, and studies the benefit value-added distribution between regional industries.

\section{Materials and Methods}

\subsection{Regional overview of the study area}

Ordos City is located in the southwest of Inner Mongolia, between $37^{\circ} 35^{\prime} 24^{\prime \prime}$ $40^{\circ} 51^{\prime} 40^{\prime \prime} \mathrm{N}$ and $106^{\circ} 42^{\prime} 40^{\prime \prime} \sim 111^{\circ} 27^{\prime} 20^{\prime \prime} \mathrm{E}$, with a total area of $86752 \mathrm{hm}^{2}$, the climate there is arid and the annual evaporation is greater than the precipitation, so it belongs to the area with serious water shortage. According to the data of water resources bulletin of Inner Mongolia from 2010 to 2019, the average annual rainfall in Ordos was $270.53 \mathrm{~mm}$, the amount of surface water resources was 470 million $\mathrm{m}^{3}$, the average amount of groundwater resources was 2.16 billion $\mathrm{m}^{3}$, and the average 
total amount of water resources was 2.39 billion $\mathrm{m}^{3}$.

As an important national energy and heavy chemical industry base, Ordos has a strong demand for industrial water, and its development is restricted by water resources. In order to solve the contradiction between supply and demand of water resources, Ordos has successively carried out two phases of water right transfer projects, lined channels at all levels, implemented efficient agricultural water-saving projects, followed the idea of "investing in water conservation and transferring water rights", and replaced agricultural water-saving rights with industrial investment water-saving projects. The transfer of the water rights is 22.3 million $\mathrm{m}^{3}$ in two phases.

In this study, the data of output value, labor force and fixed asset investment are from the statistical yearbook of Ordos City, the statistical yearbook of Inner Mongolia, the bulletin of national economic and social development of Ordos City from 1998 to 2010. The water consumption data of various industries are mainly from the bulletin of water resources of Ordos City. The water volume of water right transaction adopts the water volume of phase II water right transfer project, it comes from the planning of water right conversion and modern agricultural high efficiency and water saving project in the Yellow River Diversion Irrigation Area of Ordos City. 


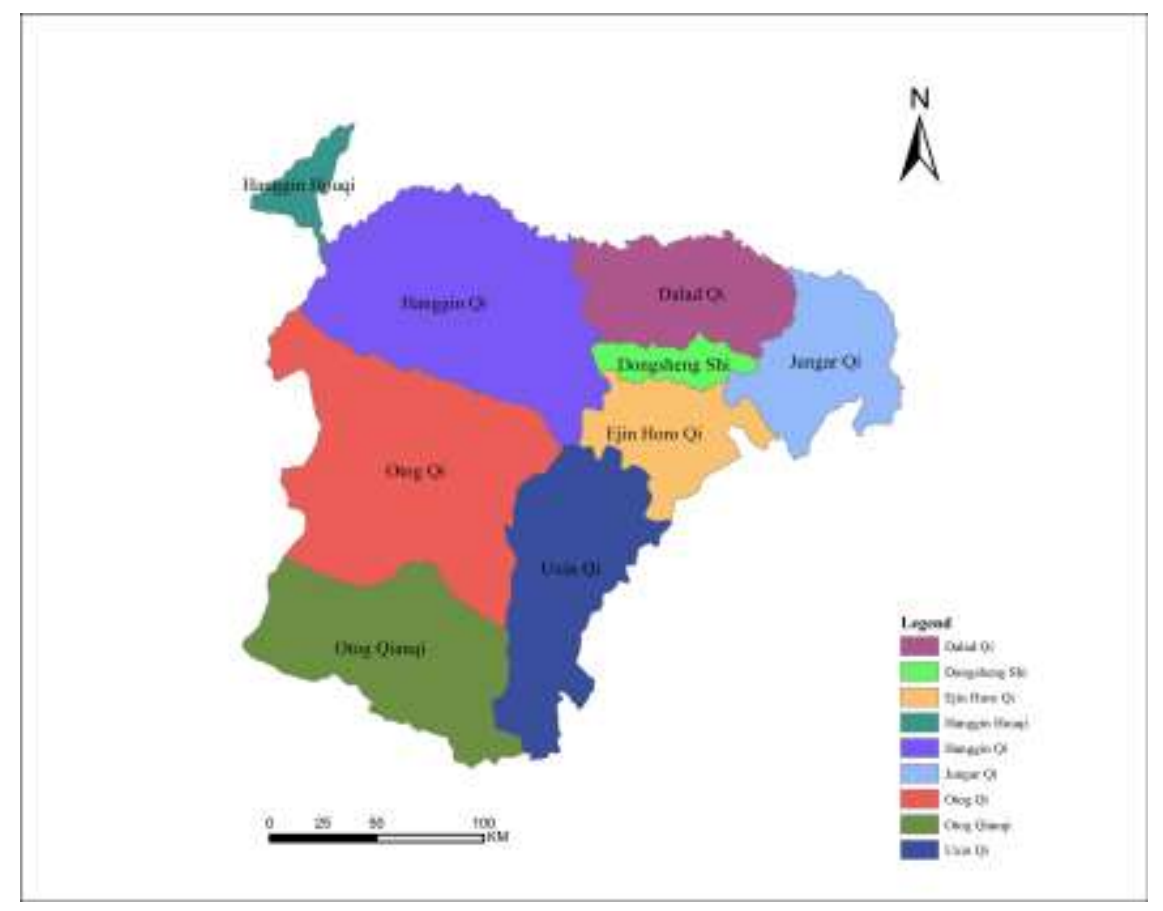

Fig. 1 Administrative division map of Ordos City, Inner Mongolia Autonomous

\subsection{Cobb-Douglas Production Function}

Cobb-Douglas production function (Gu et al. 2013; Luo et al. 2014) is used to measure the relationship between input and output of various factors in production, which is simple to calculate and has obvious significance, which is widely used in econometrics. Adding water resources to the production function as the same production factor as labor capital can be used to analyze and solve the marginal output of water resources, and then deduce the value of water resources in the industrial sector. The general form of Cobb-Douglas production function with water resources is:

$$
Y=A K^{\alpha} L^{\beta} W^{\gamma}
$$

Where, $A$ is the constant term, $K$ is the investment in fixed assets, $L$ is the labor force input, $W$ is the water resources input, $\alpha$ is the elasticity coefficient of 
fixed assets investment; $\beta$ is the elasticity coefficient of labor input; $\gamma$ is the elasticity coefficient of water resources input.

Take the logarithmic form and linearize it to obtain:

$$
\ln Y=\ln A+\alpha \ln K+\beta \ln L+\gamma \ln W
$$

The contribution of water resources input to output is separated, and the marginal benefit of water resources can be expressed as:

$$
\rho=\frac{\partial Y}{\partial W}=\frac{\partial \ln Y}{\partial \ln W} \times \frac{Y}{W}=\gamma \frac{Y}{W}
$$

This paper assumes that the return to scale remains unchanged, $\alpha+\beta+\gamma=1$, that is, the production efficiency will not increase with the expansion of production scale. Only by improving the technical level can we improve the economic benefits. Therefore, in the specific calculation, the impact of scale elasticity needs to be eliminated, and the conversion equation is:

$$
\rho=\frac{\partial Y}{\partial W}=\frac{\gamma}{\alpha+\beta+\gamma} \times \frac{Y}{W}
$$

\subsection{Improved Shapley value method}

Shapley value method (Shapley 1953) is a game analysis method used to solve the benefit distribution among multiple cooperative subjects. Suppose there are $n$ players in the cooperative game $N=\{1,2,3, \mathrm{~L}, n\}$, where $i \in N$ is a single participant and $S \in N$ is a subset of all participants. When the participants in $S$ set cooperate, $S$ is called an alliance. Use $v(S)$ to represent the benefits obtained by alliance $S$ when there is cooperation among participants. It satisfies the following properties:

$$
\text { (1) } v(\phi)=0
$$


(2) $\quad v(S \mathrm{U} T) \geq v(S)+v(T) \geq 0$

(3) If $S \in T, v(S) \leq v(T)$

That is, the larger the scale of the alliance, the greater the total income of the alliance.

Assuming that $M_{i}$ is the benefit that each participant in $S$ can get from the cooperation, the following conditions need to be met to participate in the cooperation:

$$
\begin{gathered}
\sum_{i=1}^{n} M_{i}=v(T) \\
M_{i} \geq v(i), i=1,2, \mathrm{~L}, n
\end{gathered}
$$

That is, the benefits obtained by members from cooperation are greater than those obtained when they act.

The benefits that the cooperative subject should get:

$$
\begin{gathered}
M_{\mathrm{i}}=\sum_{S \in N} w(t)[v(S \mathrm{U}\{i\}-v(S)] \\
w(t)=\frac{(n-|S|) !(|S|-1) !}{n !}
\end{gathered}
$$

Where $|S|$ represents the number of elements in $S$.

In this paper, Shapley value method is used to solve the benefit distribution problem of agricultural and industrial water rights transaction. The amount of water traded is the amount of water lost by evaporation and leakage in the water transmission process before the construction of water-saving project, so both parties have no benefits before the transaction. Therefore, the traditional Shapley value method is used to obtain the average distribution of post transaction benefit 
appreciation.

The above Shapley value method does not consider the investment proportion and shared risk of each member for the distribution of interests, which is unreasonable to a certain extent. Considering the influence of investment and risk factors, this paper improves the Shapley value method.

In terms of capital investment, the investment proportion of agriculture is $a_{1}$ and that of industry is $a_{2}$; in terms of risk bearing, the risk sharing ratio of agriculture is $b_{1}$ and that of industry is $b_{2}$.

The matrix is expressed as:

$$
Q=\left[\begin{array}{ll}
a_{1} & b_{1} \\
a_{2} & b_{2}
\end{array}\right]
$$

The influence degree of each factor on benefit distribution is expressed by weight $P$ :

$$
P=\left[\begin{array}{ll}
p_{1} & p_{2}
\end{array}\right]^{T}
$$

Revised coefficient matrix of benefit distribution of each industry after adjustment:

$$
\left[\begin{array}{ll}
r_{1} & r_{2}
\end{array}\right]^{T}=Q \times P
$$

The profit distribution value of each industry after adjustment is:

$$
\varphi_{i}=V_{\mathrm{i}}+\left(r_{i}-\frac{1}{n}\right) \times V_{\mathrm{i}}
$$

\section{Results and Discussion}

This paper is divided into four steps, firstly, the Cobb-Douglas production function is used to calculate the input elasticity of water resources, and then the marginal benefit of single cubic meter of water in each industry is obtained 
according to the output of single cubic meter of water; the second step is to calculate the benefit increment between regional industries water rights transaction. The benefit increment generated by the transfer of water rights from agriculture to industry can be obtained from the marginal benefits of unilateral water in the above different industries and the transaction water volume. The transaction water volume is the water saved by industrial enterprises investing in agricultural water conservation. The third step is to distribute the benefits between regional industries. The value-added benefits of water rights transaction should be shared by the transferor and the transferee. How to reasonably distribute between industries provides a reference for the Shapley value method in cooperative game theory. This is equivalent to a two person alliance. The income of each party in the alliance is calculated according to the weight. However, only the ability of each subject to obtain income alone is considered as the distribution weight, without considering the influence of other factors. Therefore, the fourth step is to improve the Shapley value method, and adjust the distribution results considering the different investment funds capacity of different industries.

\subsection{Marginal benefit of agricultural water resources}

Agricultural production is inseparable from the input of land factors. Cobb-Douglas production function is expressed as:

$$
X=A K^{\alpha} L^{\beta} T^{\lambda} W^{\gamma}
$$

Where, $X$ is the agricultural added value, ten thousand RMB; $A$ is the 
constant term; $K$ is the investment in fixed assets, which is expressed by the total

230 mechanical power input, ten thousand kw; $L$ is the labor force, ten thousand people;

$231 T$ is the land resources input, which is expressed by crop sowing area, thousand hm

$232^{2} ; W$ is the water resources input, which is expressed by water consumption for 233 irrigation, hundred million $\mathrm{m}^{3} ; \alpha$ is the elasticity coefficient of fixed assets

234 investment; $\beta$ is the elasticity coefficient of labor input; $\lambda$ is the elasticity

235 coefficient of land resources input; $\gamma$ is the elasticity coefficient of water resources 236 input.

Table 1 Agricultural input-output data

\begin{tabular}{|c|c|c|c|c|c|}
\hline Year & Agricultural & Land & Investment in & Labor force & Water \\
\hline & added value / & resources & fixed assets / & input / ten & resources input \\
\hline & ten thousand & input & ten thousand & thousand & hundred \\
\hline & RMB & thousand $\mathrm{hm}^{2}$ & $\mathrm{kw}$ & people & million $\mathrm{m}^{3}$ \\
\hline 1998 & 77985 & 251.2 & 104.58 & 40.96 & 9.890 \\
\hline 1999 & 78530 & 265.1 & 115.00 & 41.81 & 10.156 \\
\hline 2000 & 103655 & 260.9 & 128.73 & 41.62 & 10.356 \\
\hline 2001 & 97608 & 258.2 & 148.89 & 41.55 & 10.652 \\
\hline 2002 & 127404 & 264.5 & 155.54 & 40.3 & 10.984 \\
\hline 2003 & 162811 & 272.3 & 164.27 & 37.56 & 11.021 \\
\hline 2004 & 162593 & 323.1 & 179.98 & 33.49 & 11.267 \\
\hline 2005 & 211952 & 342.9 & 193.92 & 31.93 & 11.528 \\
\hline 2006 & 227203 & 368.0 & 205.60 & 30.61 & 11.679 \\
\hline
\end{tabular}




\begin{tabular}{llllll}
\hline 2007 & 259767 & 375.1 & 215.10 & 31.11 & 11.785 \\
2008 & 284937 & 372.1 & 237.90 & 30.09 & 11.987 \\
2009 & 300439 & 378.8 & 249.50 & 29.10 & 11.918 \\
2010 & 354264 & 379.0 & 256.88 & 27.19 & 11.824 \\
\hline
\end{tabular}

Before regression analysis, the data need to be tested for collinearity. By testing

239 the correlation of the sequence, it is found that there is a strong correlation between

240 some data, as shown in Table 2. The excessive sequence correlation indicates that

241 there may be serious multicollinearity between independent variables, so linear

242 regression analysis cannot be used. To eliminate the collinearity between variables,

243 ridge regression analysis can be used to fit the model. The results are shown in Table 2443.

Table 2 Correlation analysis results of agricultural production factors

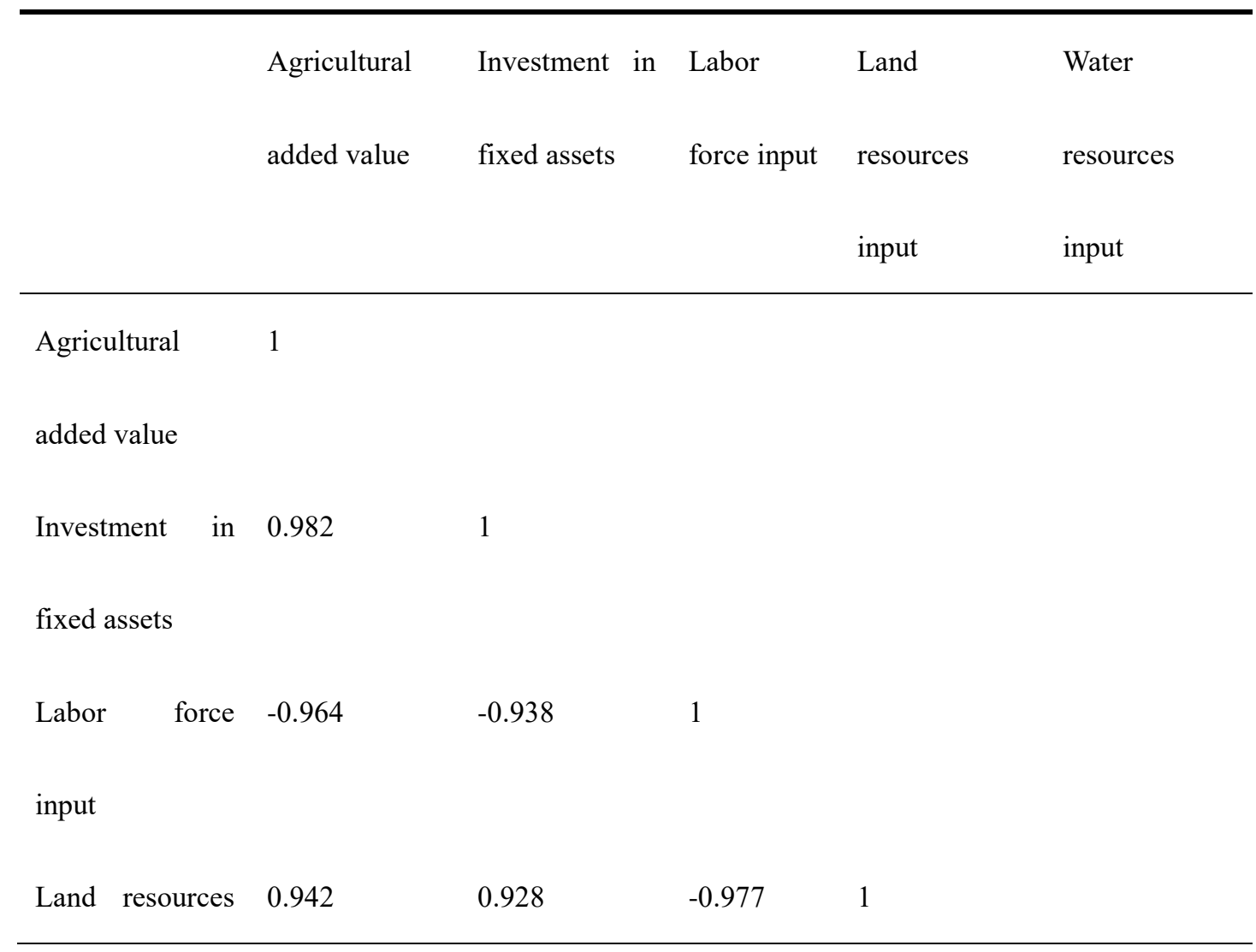


input

$\begin{array}{llllll}\text { Water resources } & 0.968 & 0.986 & -0.917 & 0.925 & 1\end{array}$

input

Table 3 Ridge regression analysis results

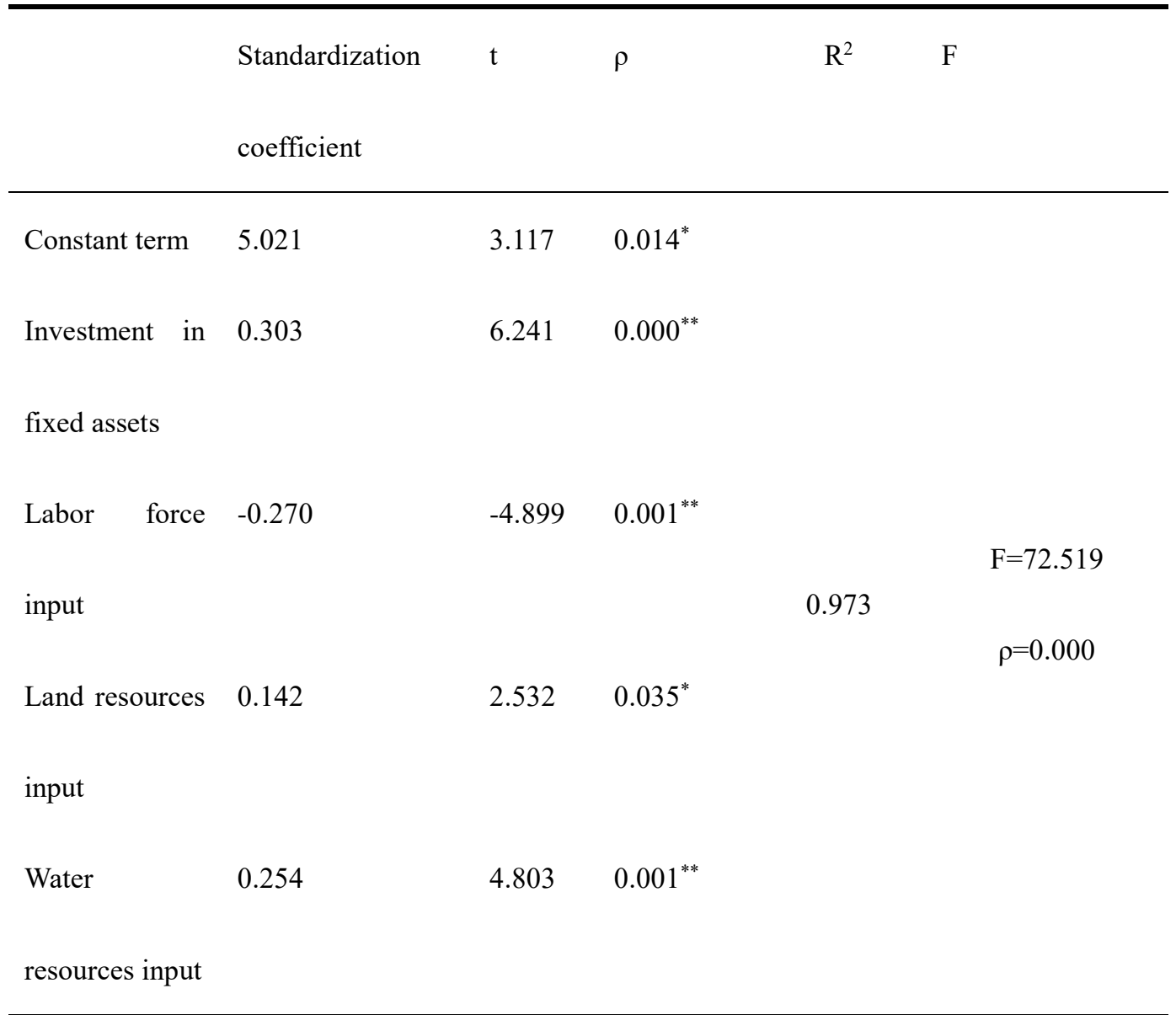

248 It can be seen from the above results, $\mathrm{F}=72.519, \rho=0.000<0.01$ (Significance

249 level), the model passed the test. Therefore, the fitting expression is:

$$
\ln X=5.021+0.303 \ln K-0.270 \ln L+0.142 \ln T+0.254 \ln W
$$

252 which the elasticity coefficient of labor input is negative, mainly because the rapid

253 development of industrialization and urbanization makes a large number of 
agricultural employees transfer from rural areas to cities and towns, the agricultural labor force decreases, and the labor price also rises sharply. The elasticity coefficient of water resources input is 0.254 , which means that the agricultural output value increases by $0.254 \%$ for every $1 \%$ increase in water consumption. In 2017 , the added value of agriculture was 664658 ten thousand RMB, and the water consumption was 9.214 hundred million $\mathrm{m}^{3}$. According to formula (4), the marginal benefit of water resources was $4.27 \mathrm{RMB} / \mathrm{m}^{3}$.

\subsection{Marginal benefits of industrial water resources}

Since industrial production technology has a great impact on output value, Cobb-Douglas production function is expressed as:

$$
Y=A K^{a} L^{b} J^{c} W^{d}
$$

Where, $Y$ is the industrial added value, ten thousand RMB; $A$ is the constant term; $K$ is the investment in fixed assets, ten thousand RMB; $L$ is the labor force input, which is expressed by the number of employees in the secondary industry, ten thousand people; $J$ is the technical input, which is expressed by the investment of scientific research funds in Ordos, ten thousand RMB; $W$ is the water resources input, which is expressed by industrial water consumption, hundred million $\mathrm{m}^{3} ; a$ is the elasticity coefficient of fixed assets investment; $b$ is the elasticity coefficient of labor force input; $c$ is the elasticity coefficient of technology input; $d$ is the elasticity coefficient of water resources input.

Table 4 Industrial input-output data

\begin{tabular}{llll}
\hline Year & Industrial & Investment in Labor force Water & Technical input \\
\hline
\end{tabular}




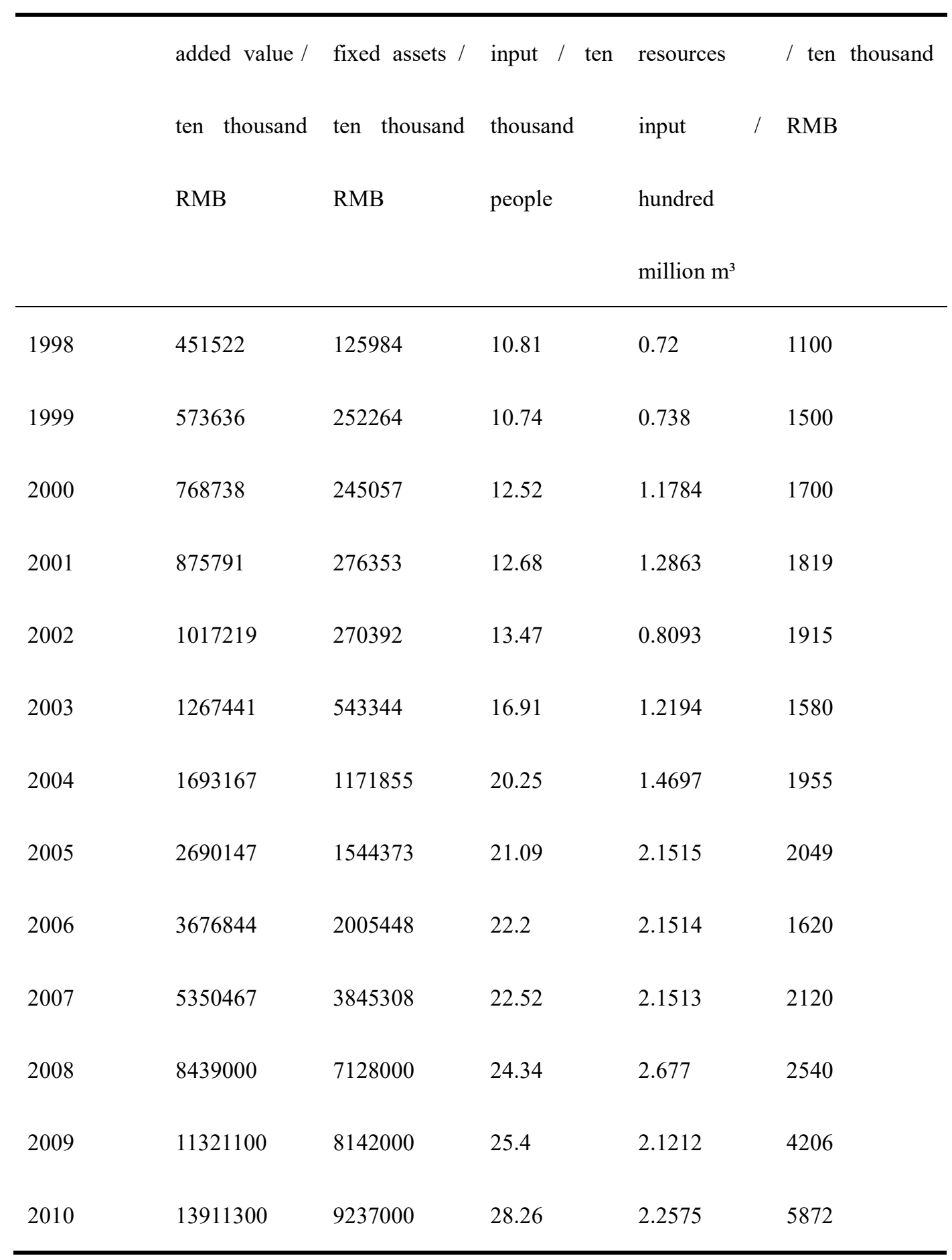

Similarly, the collinearity test is conducted on the data, and there is also serious

276 multicollinearity between independent variables, as shown in Table 5. The ridge

277 regression analysis is used to fit the model, and the results are shown in Table 6.

Table 5 Correlation analysis results of industrial production factors

Industrial Investment in Labor Technical Water




\begin{tabular}{|c|c|c|c|c|c|}
\hline & added value & fixed assets & $\begin{array}{l}\text { force } \\
\text { input }\end{array}$ & input & $\begin{array}{l}\text { resources } \\
\text { input }\end{array}$ \\
\hline Industrial added & 1 & & & & \\
\hline \multicolumn{6}{|l|}{ value } \\
\hline Investment in & 0.989 & 1 & & & \\
\hline \multicolumn{6}{|l|}{ fixed assets } \\
\hline Labor force input & 0.956 & 0.966 & 1 & & \\
\hline Technical input & 0.851 & 0.812 & 0.754 & 1 & \\
\hline Water resources & 0.898 & 0.912 & 0.926 & 0.644 & 1 \\
\hline input & & & & & \\
\hline
\end{tabular}

Table 6 Results of ridge regression analysis

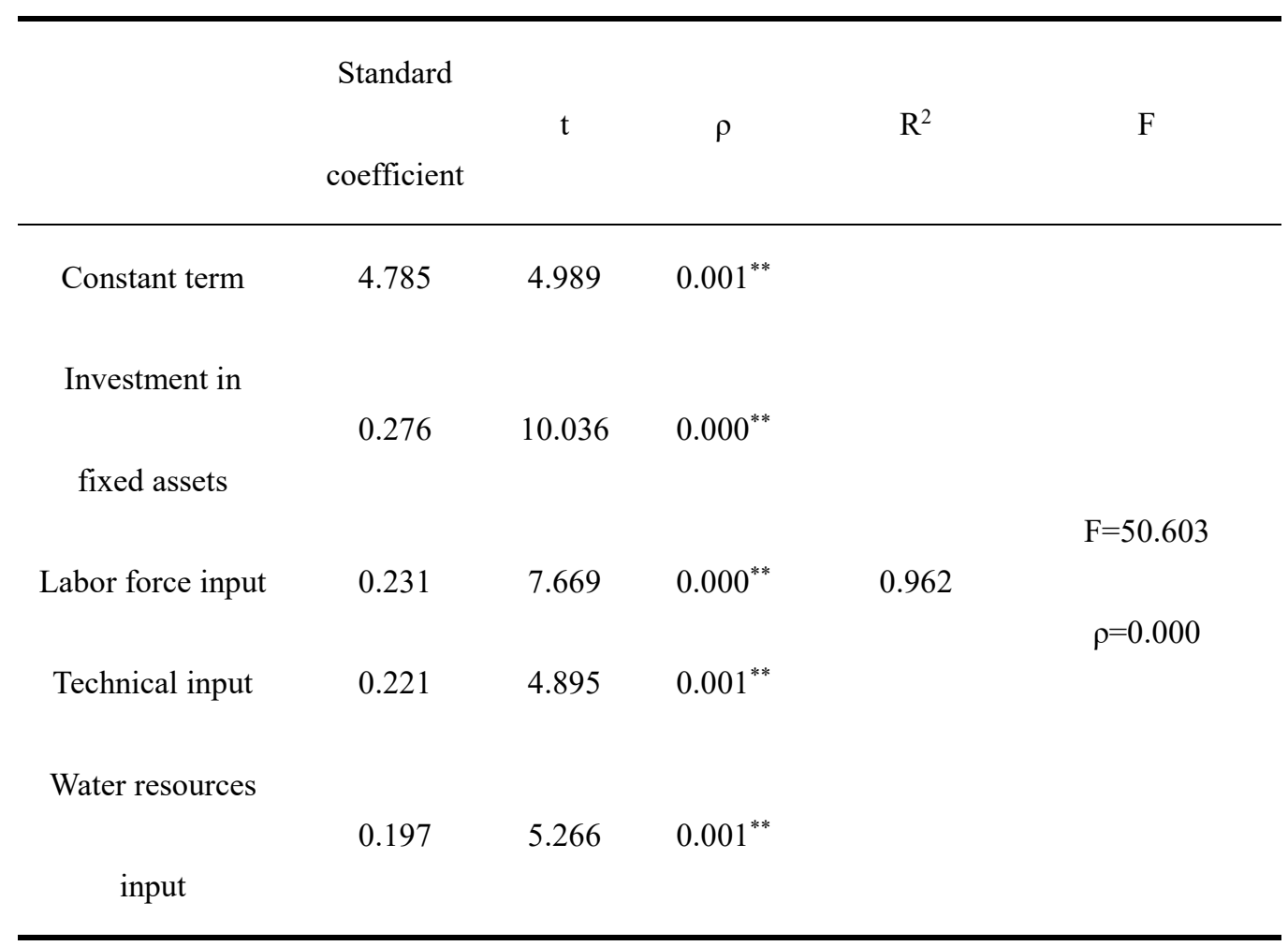

Notes: * represents $\rho<0.05,{ }^{* *}$ represents $\rho<0.01$.

281 It can be seen from the above results, $F=50.603, \rho=0.000<0.01$ (Significance 
level), the model passed the test. Therefore, the fitting expression is:

$$
\ln Y=4.785+0.276 \ln K+0.231 \ln L+0.221 \ln J+0.197 \ln W
$$

Therefore, the elasticity coefficient of water resources input is 0.197 , which means that the industrial output value increases by $0.197 \%$ for every $1 \%$ increase in water consumption. In 2017, the industrial added value was 1889.83 hundred million RMB and the water consumption was 2.5483 hundred million $\mathrm{m}^{3}$. According to formula (4), the marginal benefit of water resources was $157.94 \mathrm{RMB} / \mathrm{m}^{3}$.

\subsection{Benefit increment and distribution between regional industries} water rights transaction

After the completion of the second phase of water right transfer project in 2017, the agricultural water saving was 12332 ten thousand $\mathrm{m}^{3}$, and the water volume that can be traded to industry was 9930 ten thousand million $\mathrm{m}^{3}$. The main body of agricultural water-saving investment is industrial enterprises, with an investment of 16.5 hundred million RMB, which is used for the construction of water-saving projects.

According to the marginal benefits of agricultural and industrial water use, the added value of water right transaction can be calculated as:

$$
V=(157.94-4.27) \times 0.993-16.5=136.09 \text { (hundred million RMB) }
$$

\subsubsection{Traditional Shapley value method benefit increment distribution}

The benefit increment of water rights transaction between agriculture and industry is generated under the cooperation of two industries, which is in line with the hypothesis of Shapley value method. When the traditional Shapley value method 
is adopted, $n=2$, the benefit increment distribution of water rights transaction

305 between agriculture and industry can be obtained from formula (7) and (8). The

306 value-added distribution of industrial benefits under alliance:

$$
M_{A}=1 / 2[136.09-0]=68.045 \text { (hundred million RMB) }
$$

In the same way, the value-added distribution of industrial benefits under alliance is also 68.045 hundred million RMB.

\subsubsection{Modification of benefit distribution model based on Shapley value method}

Since the construction of water-saving projects is only invested by industrial enterprises, the investment coefficient of industrial industry for water right transaction is 1 and that of agricultural industry for water right transaction is 0 .

The risk factors of water rights transaction in agriculture and industry include the interannual change of water resources and the amount of water traded. According to relevant information, the weight of each risk factor is $\lambda=\left[\begin{array}{ll}0.108 & 0.892\end{array}\right]$. For the risk of interannual change of water resources, agriculture and industry bear the same proportion, both of which are 0.5 . The risk of transaction water volume is expressed by the proportion of transaction water volume in agricultural and industrial water. Agriculture is $9930 / 92214=0.108$; Industry is $9930 / 25483=0.390$, after normalization, agriculture: industry is $=0.217: 0.783$.

The sharing coefficient matrix of agriculture and industry for each risk factor is:

$$
\begin{gathered}
B=\left[\begin{array}{ll}
0.5 & 0.217 \\
0.5 & 0.783
\end{array}\right] \\
B \times \lambda^{T}=\left[\begin{array}{l}
0.248 \\
0.752
\end{array}\right]
\end{gathered}
$$




$$
Q=\left[\begin{array}{ll}
0 & 0.248 \\
1 & 0.752
\end{array}\right]
$$

According to expert assessment, the impact of investment and risk factors on benefit distribution: $P=\left[\begin{array}{ll}0.7 & 0.3\end{array}\right]^{T}$

$$
Q \times P=\left[\begin{array}{l}
0.074 \\
0.926
\end{array}\right]
$$
adjustment is: agriculture after the amendment is 39.058 hundred million RMB and that of industry is 97.032 hundred million RMB. The benefit distribution of each industry is more reasonable than that under the equal sharing of investment and risk, and the sum of overall income of water rights transaction, so the model improvement is rigorous.

\subsection{Analysis and Discussion}

\subsubsection{Analysis of distribution results of Shapley value method before and after}

\section{improvement}

The water right transaction between agriculture and industry only involves two participants, and their benefits are distributed by the traditional Shapley value method, resulting in equal benefits. However, because the contribution of water 
resources to agricultural output is far lower than that of industry, and industrial investment in agricultural water conservation replaces agricultural water conservation, this result is unfavorable to the long-term sustainability of water right transaction. In this paper, the distribution result of Shapley value method is modified by investment proportion and risk sharing coefficient. After adjustment, the proportion of water right transaction income allocated by industry and agriculture is 0.713:0.287, and industry allocates 57.974 hundred million RMB more than agriculture (as shown in Figure 2). The corresponding investment proportion of industry is 1 , agriculture is 0 , the risk proportion borne by industry is 0.752 and agriculture is 0.248 , the results are fair and reasonable (as shown in Table 7).

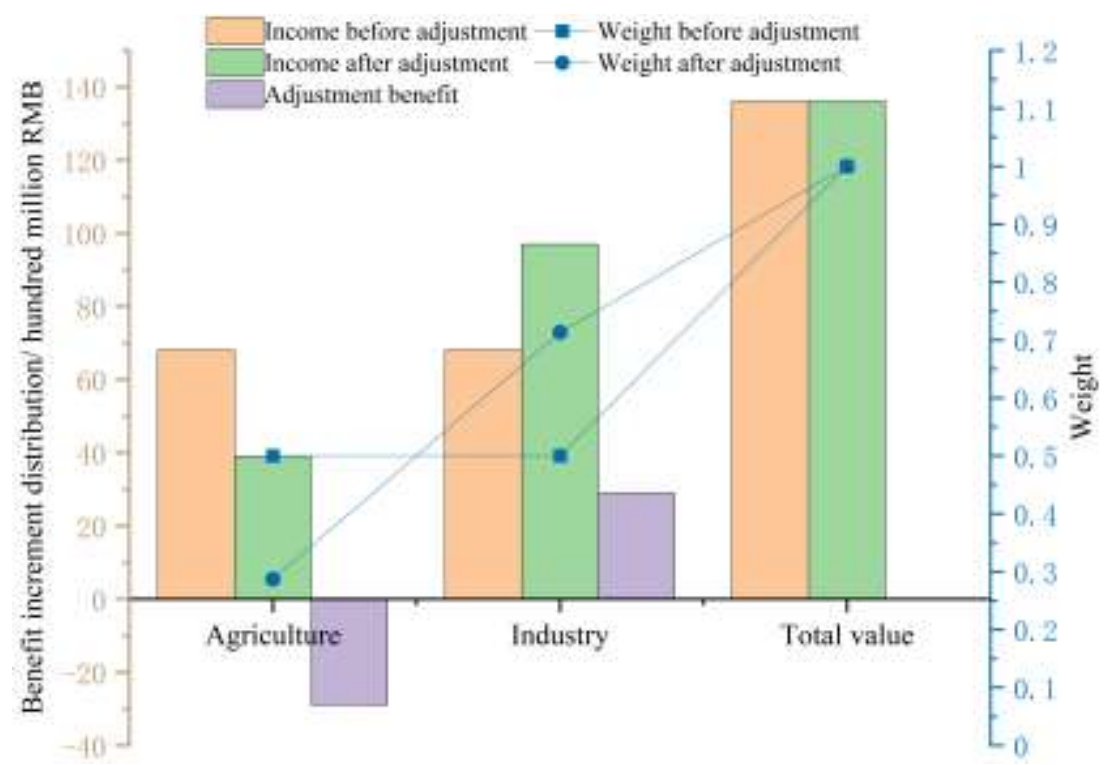

Fig. 2 Distribution of benefit increment before and after the improvement of Shapley

Table 7 The results of benefit increment distribution after the improvement of Shapley value method

\begin{tabular}{|c|c|c|c|c|}
\hline Category & Investment & Risk allocation & correction & Benefit distribution / \\
\hline
\end{tabular}




\begin{tabular}{lllll}
\hline & proportion & & factor & billion RMB \\
\hline Agriculture & 0 & 0.248 & 0.074 & 3.9058 \\
Industry & 1 & 0.752 & 0.926 & 9.7032 \\
\hline
\end{tabular}

361

\subsubsection{Analysis on Influencing Factors of benefit distribution}

This paper only considers the capital investment, the risk of interannual variation of water resources and the risk of traded water volume for the factors affecting the distribution of the value-added distribution of water rights transaction. In addition, there may be the risk that the total amount of water exceeds the standard, the risk that industrial water will occupy agricultural water, and the risk that agricultural water saving will have an impact on the ecology. In addition, because the water rights transaction market is not perfect, there may be policy risks, legal risks, technical risks and so on. As for how to determine the proportion and weight of each risk element, it needs to be further studied in the future.

\section{Conclusions}

The benefit increment distribution of regional inter-industry water rights transaction is related to social fairness and the sustainable development of water rights transaction. In order to approach the real value of water resources as much as possible, this paper calculates the marginal benefits of agricultural and industrial water use according to Cobb-Douglas production function, and then obtains the benefit increment of inter industry water right transaction under tradable water volume. At the same time, the benefit distribution between industries adopts the improved Shapley value method, which considers the influence of investment factors 
and risk factors.

The results show that the marginal benefit of industrial water is $157.94 \mathrm{RMB} /$ $\mathrm{m}^{3}$, which is far greater than that of agricultural water by $4.27 \mathrm{RMB} / \mathrm{m}^{3}$, the contribution rate of water resources to industry is far greater than that of agriculture. Trade water rights between agriculture and industry to make agricultural water resources flow to industry, which can increase the use value of water resources. The value-added benefits of water rights transaction are allocated to agriculture of 39.058 hundred million RMB and industry of 97.032 hundred million RMB. The improved Shapley value method can ensure the fairness of distribution, so that the transferee can get benefits and ensure the transferor to get reasonable compensation at the same time. This paper mainly studies the value-added benefits brought by the water rights transaction among the regional industries and the fair distribution among the industries from a theoretical point of view. How to effectively combine the benefit distribution and the price formation mechanism in the future still needs to continue to be studied.

Ethical Approval Informed consent.

Consent to Participate Informed consent.

Consent to Publish Informed consent.

Authors Contributions Conceptualization: Wenge Zhang; Methodology: Xinjian Guan and Qiongying Du; Formal analysis and investigation:Qiongying Du and Wenge Zhang; Writing - original draft preparation: Wenge Zhang, Baoyong Wang 
and Qiongying Du; Writing - review and editing: Xinjian Guan, Baoyong Wang and Qiongying Du; Resources: Wenge Zhang; Supervision: Xinjian Guan.

Funding This research was funded by the National Natural Science Foundation of China (No. NSCF-51979119) and by the Basic R\&D Special Fund of Central Government for Non-profit Research Institutes (HKY-JBYW-2020-17)..

Availability of data and materials All data and materials support our published claims and comply with field standards.

\section{Conflict of Interest None.}

\section{Reference}

Archibald S O , Renwick M E .(1998). Expected Transaction Costs and Incentives for Water Market Development[M]. Markets for Water, 95-117. Doi: https://doi.org/10.1007/978-0-585-32088-5 7.

Chen Hongzhuan, Yang Xianghui, Yang Zhen. (2006). Game analysis on pricing decision of water rights transaction in China[J], Systems Engineering, (04):53-57. Doi: https://doi.org/10.3969/j.issn.1001-4098.2006.04.011 .

Curiel I. (1997). Cooperative Game Theory and Applications. Springer, Doi: https://doi.org/10.1007/978-1-4757-4871-0 .

Chen Jinghui. (2008). The benefit compensation mechanism of water resource "from agriculture to non-agriculture". Zhejiang Gongshang University. Doi: https://doi.org/10.7666/d.Y1524311.

Dimitrov D. (2005). Models in Cooperative Game Theory. Springer Berlin 
Easter K W , Rosegrant M W , Dinar A. (1998). Markets for Water: Potential and

Publishers,

Doi: https://doi.org/110.1007/b102479.

Gu L. (2013). Minimax Curve Fitting Method in Application of C-D Production Function-With the Grain Yield Data in China as the Example. journal of modern agriculture, 2(3):42-52.

Guo F, Chen XD, Liu R, et al. (2021). Study on water quality and water quantity bivariate water right transaction model. Yellow River, 43(02):79-83.

$\mathrm{Gu}$ YP. (2019). Research on water rights transaction mode based on the perspective of options. XiAn Industrial University, Doi: https://doi.org/10.27391/d.cnki.gxagu.2019.000176.

$\mathrm{Hu} \mathrm{XH}$, Ji CM, Wang LP. (2010). Analysis of water rights transaction among agricultural users based on optimization and game theory. Journal of Hydraulic Engineering, 41(05):608-612+618. https://doi.org/10.13243/j.cnki.slxb.2010.05.007.

Kuang YH. (2015). Water rights transaction should pay more attention to water quality than water quantity. Environmental Economy, (Z7):21.

Lin C , O'Reilly L, Dollery B. (2000). Water markets as a vehicle for water reform: the case of New South Wales. Australian Journal of Agricultural and Resource Economics, 44(2). Doi: https://doi.org/10.1111/1467-8489.00113.

Liu G , Liu Y, Shi Y B , et al. (2017). Empirical study on double layer dynamic 
game price decision mechanics of water rights transaction under Quasi-Market. China Population, Resources and Environment, Doi: https://doi.org/10.12062/cpre.20170326.

Liu XC. (2018). Research on the trade of industrial and agricultural water rights. Shandong Agricultural University.

Luo GW , Tian Y , Yun JI. (2014). Based on Factor Analysis and the Economic Growth Research of C-D Production Function-Take the West for a Case[J]. Journal of Chongqing Normal University (Natural Science), 31(01). Doi: https://doi.org/10.11721/cqnuj20140124.

Ma YX. (2016). Study on benefit distribution method of water resources trans-regional transfer based on Shapley value method. China Population, Resources and Environment, 26(10):116-120. DOI: https://doi.org/10.3969/j.issn.1002-2104.2016.10.015.

Meng G, Wang XJ. (2009). Analysis on the efficiency of water rights transaction. Systems Engineering, 27(05):121-123.

Parrachino I , Dinar A , F Patrone. (2006). Cooperative game theory and its application to natural, environmental, and water resource issues : 1 . basic theory. Policy Research Working Paper Series, 33(11):1-46(46). Doi: https://doi.org/10.1596/1813-9450-4072.

Ringler C. (2001). Optimal allocation and use of water resources in the Mekong river basin: multi-country and intersectoral analysis. 
Shapley LS. (1953). A value for n-person games. Contributions to the Theory of Games.

Tan L. (2019) Study on the calculation model of dual water right transaction price driven by agricultural water saving in irrigated district. Zhengzhou University.

Tian GL, Wei D. (2019). Bargaining model and simulation of water rights transaction negotiation based on Bayesian learning model. Journal of Economics of Water Resources, 37(01):26-31+80.

Wang X, Yang S. (2018). Research on status quo of water rights transaction in China. Iop Conference, 171. Doi: https://doi.org/10.1088/1755-1315/171/1/012033.

Wu FP, Li Y. (2019). Study on the basic pricing model of water rights transaction based on the shadow price of buyer and seller. Soft Science, 33(08):85-89. Doi: https://doi.org/10.13956/j.ss.1001-8409.2019.08.153.

Zhang JB, Liu QH. (2018). The development logic of two-dimensional water rights quasi-market transactions in the Yellow River area of Inner Mongolia[J]. Research On Development, (03):46-52. Doi: https://doi.org/10.13483/j.cnki.kfyj.2018.03.008.

Zhang JB, Zhang YL, Zhu XM. (2020). Realistic consideration and policy choice of "unification of quantity and quality" management of water right transaction. Water Resources Development Research, v.20; No.224(02):34-38. Doi: https://doi.org/10.13928/i.cnki.wrdr.2020.02.007.

Zhang JL. (2019). Study on evaluation of cross-regional water rights transaction potential and transaction model in Henan Province. Zhengzhou University. 